\title{
Proteomic analysis of surface proteins of Trichinella spiralis muscle larvae by two-dimensional gel electrophoresis and mass spectrometry
}

\author{
Jing Cui ${ }^{1 *}$, Ruo Dan Liu', Li Wang ${ }^{1}$, Xi Zhang ${ }^{1}$, Peng Jiang ${ }^{1}$, Ming Yuan Liu² and Zhong Quan Wang ${ }^{\text {** }}$
}

\begin{abstract}
Background: Trichinella spiralis is a zoonotic tissue-dwelling parasitic nematode that infects humans and other mammals. Its surface proteins are recognized as antigenic in many infected hosts, being directly exposed to the host's immune system and are the main target antigens that induce the immune responses. The larval surface proteins may also interact with intestinal epithelial cells and may play an important role in the invasion and development process of $T$. spiralis. The purpose of this study was to analyze and characterize the surface proteins of T. spiralis muscle larvae by two-dimensional gel electrophoresis (2-DE) and mass spectrometry.

Methods: The surface proteins of T. spiralis muscle larvae were stripped from the cuticle of live larvae by the cetyltrimethylammonium bromide (CTAB) and sodium deoxycholate. The surface protein stripping was examined by an immunofluorescent test (IFT). The surface proteins were analyzed by SDS-PAGE and Western blotting, and then identified by 2-DE and MALDI-TOF/TOF mass spectrometry analysis.

Results: The IFT results showed that the surface proteins-stripped larvae were not recognized by sera of mice immunized with surface antigens. Western blotting showed 7 of 12 protein bands of the surface proteins were recognized by mouse infection sera at $18 \mathrm{dpi}$ and at $42 \mathrm{dpi}$. The 2-DE results showed that a total of approximately 33 proteins spots were detected with molecular weights varying from 10 to $66 \mathrm{kDa}$ and isoelectric point (pl) from 4 to 7. Twenty-seven of 33 protein spots were identified and characterized to correlate with 15 different proteins. Out of the 14 proteins identified as T. spiralis proteins, 5 proteins (partial P49 antigen, deoxyribonuclease II family protein, two serine proteases, and serine proteinase) had catalytic and hydrolase activity. All of these 5 proteins were also associated with metabolic processes and 2 of the five proteins were associated with cellular processes.

Conclusions: In this study, T. spiralis muscle larval surface proteins have been identified, which will provide useful information to elucidate the host-parasite interaction, identify the invasion-related proteins, early diagnostic antigens and the targets for a vaccine.
\end{abstract}

Keywords: T. spiralis, Muscle larvae, Surface proteins, Mass spectrometry

\section{Background}

Trichinella spiralis is a tissue-dwelling parasitic nematode infecting many kinds of carnivores and omnivores, and is the main causative agent of trichinellosis. Humans acquire the disease by the ingestion of raw or insufficiently cooked meat containing the $T$. spiralis infective larvae [1]. Once ingested, muscle larvae are released

\footnotetext{
*Correspondence: cuij@zzu.edu.cn; wangzq@zzu.edu.cn

'Department of Parasitology, Medical College, Zhengzhou University, 40 Daxue Road, Zhengzhou 450052, P. R. China

Full list of author information is available at the end of the article
}

from their capsules in the stomach by the digestive enzymes. Then, the muscle larvae invade, occupy and migrate through intestinal epithelium cells where they undergo four molts to emerge as sexually mature adults [2]. The establishment of T. spiralis in this habitat is the key step in which the larvae infect the hosts. With regard to the intestinal stage of infection, it has been suggested that proteases participate in intestinal invasion by $T$. spiralis $[3,4]$. Although it has been known for many years that $T$. spiralis larvae invade the intestinal epithelium and the in vitro model of epithelial 
invasion by the larvae has been developed [5,6], the mechanisms by which $T$. spiralis infective larvae recognize, invade, and migrate within the intestinal epithelium are unknown.

Previous studies had showed that the cuticle surface of parasitic nematodes is recognized as antigenic in many infected hosts $[7,8]$. In a number of experimental systems antibodies are produced against surface molecules and mediate antibody dependent cell mediated cytotoxic reactions [9]. T. spiralis surface proteins are directly exposed to the host's immune system, are the main target antigens which induce the immune responses, and may play an important role in the invasion and development process of $T$. spiralis larvae. There has been special interest to study the $T$. spiralis surface proteins that interact at the interface between the parasite and the host to modify the environment, either by modulating the host immune response or even host cell gene expression, to ensure parasite invasion, development and survival $[10,11]$. The surface proteins may also be involved in the larvae-nurse cell complex formation and maintenance during the muscular stage of the infection. Therefore, analysis of $T$. spiralis muscle larval surface proteins and characterization of their molecular function and biological process could provide important information to elucidate the mechanism of parasite invasion and possibly identify invasion-related proteins, early diagnostic antigens and potential targets for a vaccine.

Recently, proteomic approaches are being used to complement genetic studies on T. spiralis [12]. As effective tools for proteomics, the two-dimensional electrophoresis (2-DE) combined with mass spectrometry (MS) has been widely used to characterize the differential expression profiles of different species of Trichinella spp. [13-17]. Because the excretory- secretory (ES) proteins were easily prepared by the in vitro cultivation of Trichinella muscle larvae, the ES proteins were usually analyzed by utilizing 2-DE techniques $[18,19]$. To our knowledge, no surface proteins of $T$. spiralis muscle larvae have been analyzed and identified by 2-DE and mass spectrometry.

In this study, the surface proteins of T. spiralis muscle larvae were firstly stripped and analyzed, then identified and characterized by the 2-DE combined with Matrixassisted laser desorption ionization (MALDI)-time-of-flight (TOF)/TOF-MS approach. It is therefore of fundamental importance for further studies of the surface protein functions on the invasion, survival, and development of $T$. spiralis and the early diagnostic markers for trichinellosis.

\section{Methods}

\section{Parasite and experimental animals}

Trichinella spiralis isolate (ISS534) used in this study was obtained from a domestic pig in Nanyang city of Henan Province, China. The isolate was maintained by serial passages in Kunming mice in our laboratory. Six-week-old male Kunming mice were obtained from the Experimental Animal Center of Henan Province (Zhengzhou, China). The mice were maintained under specific pathogen-free conditions with sterilized food and water.

\section{Collection of infection sera}

$\mathrm{BALB} / \mathrm{c}$ mice were orally infected with 300 muscle larvae/ mouse and the serum samples from the infected mice were collected as described previously [20]. About $100 \mu \mathrm{l}$ of tail vein blood was collected daily from each mouse before infection and during 14-21 days post infection (dpi), respectively. When the forty infected mice were sacrificed at $42 \mathrm{dpi}$ by deep ether anesthesia, their serum samples were also collected. Anti-Trichinella IgG antibodies in sera from infected mice at 14-21 dpi were assayed by ELISA and Western blot. The specific antibodies were firstly detected at $18 \mathrm{dpi}$ and persisted to $42 \mathrm{dpi}$ by the above-mentioned two methods, and then these sera collected at $18 \mathrm{dpi}$ and $42 \mathrm{dpi}$ were used to detect the following surface proteins.

\section{Preparation of surface, ES and somatic proteins}

The muscle larvae were recovered from the mice infected with $300 \mathrm{~T}$. spiralis infective larvae at $42 \mathrm{dpi}$ by artificial digestion of carcasses with $1 \%$ pepsin $(1: 3,000)$ and $1 \%$ hydrochloric acid as described previously [20,21]. Muscle larval surface proteins were prepared as the previously described method with some modification [8,22]. Briefly, the live muscle larvae were cultured in phosphate-buffered saline (PBS; pH 7.4, 1/15 mol/L) contained $0.25 \%$ cetyltrimethylammonium bromide (CTAB;Sigma, USA) and $2 \%$ sodium deoxycholate (Sigma, USA) at $37^{\circ} \mathrm{C}$ for $2.5 \mathrm{~h}$. The supernatant was obtained by centrifugation at $4^{\circ} \mathrm{C}$, $11,000 \times \mathrm{g}$ for $20 \mathrm{~min}$, and dialyzed against deionized water at $4^{\circ} \mathrm{C}$ for 2 days.

The ES proteins of $T$. spiralis muscle larvae were prepared as described previously [23]. In brief, after washing thoroughly in sterile saline, the larvae were again washed four times in serum-free RPMI-1640 medium supplemented with $100 \mathrm{U}$ penicillin/ml and $100 \mu \mathrm{g}$ streptomycin/ $\mathrm{ml}$. The larvae were incubated in the same medium at concentration of 5000 worms $/ \mathrm{ml}$ for $18 \mathrm{~h}$ at $37^{\circ} \mathrm{C}$ in $5 \% \mathrm{CO}_{2}$. After incubation, the media containing the ES products were filtered through a $0.2 \mu \mathrm{m}$ membrane into a $50-\mathrm{ml}$ conical tube, then centrifuged at $4^{\circ} \mathrm{C}, 15,000 \times \mathrm{g}$ for $30 \mathrm{~min}$. The supernatant was dialyzed against deionized water at $4^{\circ} \mathrm{C}$ for 2 days.

The supernatant containing surface or ES proteins were concentrated by a vacuum concentration and freeze drying (Heto Mxi-Dry-Lyo, Denmark). The protein concentration of surface proteins $(4.62 \mathrm{mg} / \mathrm{ml})$ or ES proteins $(1.26 \mathrm{mg} / \mathrm{ml})$ was determined by the method described by 
Bradford [24]. The surface or ES proteins were aliquoted and stored at $-20^{\circ} \mathrm{C}$ before use.

Somatic proteins were prepared from $T$. spiralis muscle larvae resuspended in deionized water. The suspension was submitted to 5 cycles of freezing-thawing. The larvae were homogenized on ice in a glass tissue grinder. After this, the larval fragments were further homogenized with ultrasonication (99 times 3-s cycle, $100 \mathrm{~W}, 0^{\circ} \mathrm{C}$ ). The supernatant was collected after centrifugation at $15,000 \mathrm{~g}$ for $1 \mathrm{~h}$ at $4^{\circ} \mathrm{C}$. The protein concentration of somatic proteins $(1.25 \mathrm{mg} / \mathrm{ml})$ was determined by the method described by Bradford [24].

\section{Generation of mouse immune sera to surface proteins}

Ten male BALB/c mice were used in this study. Preimmune serum samples were collected by tail bleeding 2 days prior to the first immunization. BALB/c mice were subcutaneously immunized with $20 \mu \mathrm{g}$ of surface proteins emulsified with complete Freund's adjuvant (FCA), followed by three boosts with the same amount of protein emulsified with incomplete FCA at 10-day intervals. Seven days after the last boost, mice were bled and the sera were collected [4].

\section{Immunofluorescent test (IFT)}

IFT was used to detect the stripped surface proteins of $T$. spiralis muscle larvae. The normal and surface proteins-stripped muscle larvae were collected respectively, and were fixed in $4 \%$ paraformaldehyde. The whole muscle larvae were blocked with $5 \%$ normal goat serum in PBS and then incubated in a moist chamber at $37^{\circ} \mathrm{C}$ for $1 \mathrm{~h}$ with a 1:10 dilution of immune and normal sera. After washing three times in PBS, the larvae were incubated with a 1:20 dilution of FITC-labeled goat antimouse IgG (Santa Cruz, USA), washed five times in PBS, and examined under a fluorescent microscope (Olympus, Japan) [25].

\section{SDS-PAGE and Western blotting}

Protein samples including surface, ES or somatic proteins were diluted with loading buffer $(250 \mathrm{mM}$ Tris- $\mathrm{HCl}$ $\mathrm{pH}$ 6.8, 50\% glycerol, 10\% SDS, 5\% 2-mercaptoethanol, $0.5 \%$ bromophenol blue) up to a concentration of $15 \mu \mathrm{g} /$ lane. After cooling, the proteins were separated by SDSPAGE on $12 \%$ acrylamide separating gel and $5 \%$ acrylamide stacking gels $(83 \times 73 \times 1.0 \mathrm{~mm})$ in a Mini-PROTEAN 3 Cell electrophoresis unit (Bio-Rad, USA) at $120 \mathrm{~V}$ for $2.5 \mathrm{~h}$ [26]. After electrophoresis, the gel was stained with $0.25 \%$ Coomassie brilliant blue R-250 (Sigma, USA) for $4 \mathrm{~h}$, and then bleached with the eluate $(100 \mathrm{~mL}$ acetic acid, $50 \mathrm{~mL}$

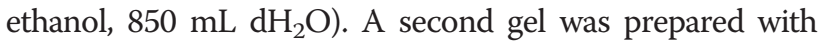
the above-mentioned proteins.

After electrophoresis, proteins were transferred to nitrocellulose membrane (Millipore, USA). After blotting, the membranes were stained with Ponceau $\mathrm{S}$ to verify transfer and to locate the protein marker and cut into strips. Each strip was blocked with $5 \%$ skimmed milk in Tris-Buffered Saline with Tween-20 (TBST) at $37^{\circ} \mathrm{C}$ for $2 \mathrm{~h}$, and incubated overnight with 1:100 dilutions of the different mouse sera. After washing, the strips were incubated at $37^{\circ} \mathrm{C}$ for $1 \mathrm{~h}$ with HRP-conjugated goat anti-mouse IgG (1:5000 dilution; Southern Biotechnology, USA), and finally with 3, 30-diaminobenzidine tetrahydrochloride (DAB; Sigma). The reaction was finally stopped by washing the strips with distilled water.

\section{2-DE and image analysis}

The surface antigens were precipitated using trichloroacetic acid (TCA) and acetone as for the previously described method with some modifications [27]. Briefly, the sample was suspended in 10\% TCA in acetone with $20 \mathrm{mM}$ DTT at $-20^{\circ} \mathrm{C}$ for $2 \mathrm{~h}$. After centrifugation at $15,000 \mathrm{~g}$ at $4{ }^{\circ} \mathrm{C}$ for $15 \mathrm{~min}$, the pellet was resuspended in cold acetone containing $20 \mathrm{mM}$ DTT and washed three times. The final pellet was air-dried. The 2-DE was performed as previously described [15]. In brief, the pellet was suspended in rehydration buffer [7 M urea, $2 \mathrm{M}$ thiourea, 4\% CHAPS, $65 \mathrm{mM}$ DTT, 0.2\% IPG buffer (pH 3-10) and 0.001\% bromophenol blue], containing $800 \mu \mathrm{g}$ of the protein samples in a total volume of $500 \mu \mathrm{l}$ and centrifuged at $12,000 \mathrm{~g}$ for $10 \mathrm{~min}$ at room temperature to remove the insoluble materials. The supernatant was loaded onto $24 \mathrm{~cm}$ pH 4-7 immobilized $\mathrm{pH}$ gradient (IPG) strips (Bio-Rad, USA) by over-night reswelling and separated by isoelectric focusing (IEF) using a Protean IEF Cell (Bio-Rad, USA). IEF was performed using a Protean IEF Cell at $20^{\circ} \mathrm{C}$ as follows: S1: 250 V, 30 min; S2: 500 V, 30 min; S3: 1000 V, 1 h; S4: 10000 V, 5 h; and S5: 10 $000 \mathrm{~V}, 60000 \mathrm{Vh}$ (using a limit of $50 \mu \mathrm{A} /$ strip). After IEF, the IPG strips were equilibrated sequentially, first in equilibration buffer (6 M urea, $0.375 \mathrm{M}$ Tris- $\mathrm{HCl} \mathrm{pH}$ 8.8, $2 \%$ SDS and 20\% glycerol) containing 2\% dithiothreitol, then in equilibration buffer containing $2.5 \%$ iodoacetamide. The second dimension was performed on 12\% SDS-PAGE using a Mini Protean cell (Bio-Rad, USA). Proteins were separated for $30 \mathrm{~min}$ at $16 \mathrm{~mA}$ and then at $24 \mathrm{~mA}$ until the dye front reached the bottom of the gel at $16^{\circ} \mathrm{C}$. After 2-DE, proteins were stained with Coomassie blue R-250 for proteomic analysis as previously described [26]. The gel was scanned using ImageScanner (GE healthcare, USA). Spot detection and spot matching were performed by using Image Master 2D Platinum 6.0 (GE healthcare, USA). Three replicates were run for the sample. Only those protein spots that were clearly observed in three independent experiments were chosen for further analysis.

\section{2-DE gel excision and tryptic digestion}

2-DE gel electrophoresis protein spots were prepared for MALDI-TOF/TOF-MS analysis according to standard 
protocols [28]. Thirty-three spots were excised manually from the Coomassie blue-stained gels. The excised gel pieces carrying the spots were placed in a tube, destained for $20 \mathrm{~min}$ in $200 \mathrm{mmol} / \mathrm{L} \mathrm{NH}_{4} \mathrm{HCO}_{3} / 30 \%$ acetonitrile and then lyophilized. All the lyophilized samples were digested overnight at $37^{\circ} \mathrm{C}$ with $12.5 \mathrm{ng} / \mathrm{ml}$ trypsin in $25 \mathrm{mmol} / \mathrm{L} \mathrm{NH}_{4} \mathrm{HCO}_{3}$. The peptides were extracted three times with $60 \%$ ACN $/ 0.1 \%$ trifluoroacetic acid (TFA). The extracts were pooled and dried completely by centrifugal lyophilization.

\section{Protein identification by MALDI-TOF/TOF-MS}

The resulting peptides from the above extraction were analyzed by MALDI-TOF/TOF-MS. The procedures were performed as described previously [16]. Briefly, The purified tryptic peptide samples were spotted onto stainless steel sample target plates and mixed (1:1 ratio) with a matrix consisting of a saturated solution of a-cyano-4hydroxy-trans-cinnamic acid in 50\% acetonitrile- $1 \%$ TFA. Peptide mass spectra were obtained on an Applied Biosystem Sciex 4800 MALDI-TOF/TOF mass spectrometer (Applied Biosystems, USA). Data were acquired using a CalMix5 standard to calibrate the instrument (ABI4700 Calibration Mixture). The MS spectra were recorded in reflector mode in a mass range from 800 to 4000 with a focus mass of 2000 . For MS/MS spectra, up to 10 of the most abundant precursor ions per sample were selected as precursors for MS/MS acquisition, excluding the trypsin autolysis peaks and the matrix ion signals. In MS/MS positive ion mode, for one main MS spectrum, 50 subspectra with 50 shots per subspectrum were accumulated using a random search pattern.
Collision energy was $2 \mathrm{kV}$, collision gas was air, and default calibration was set by using the Glu1-Fibrino-peptide $\mathrm{B}([\mathrm{M}+\mathrm{H}]+1,570.6696)$ spotted onto Cal 7 positions of the MALDI target. Combined peptide mass fingerprinting (PMF) and MS/MS queries were performed by using the MASCOT search engine 2.2 (Matrix Science, UK) and submitted to MASCOT Sequence Query server (http:// www.matrixscience.com) for identification against nonredundant NCBI database (http://www.ncbi.nlm.nih.gov/ BLAST) with the following parameter settings: $100 \mathrm{ppm}$ mass accuracy, trypsin cleavage (one missed cleavage allowed), carbamidomethylation set as fixed modification, oxidation of methionine was allowed as variable modification, and MS/MS fragment tolerance was set to $0.4 \mathrm{Da}$. The criteria for successfully identified proteins were as follows: ion score confidence index (CI) for peptide mass fingerprint and MS/MS data was $\geq 95 \%$.

\section{Ethics statement}

All animals were treated in strict accordance to the National Guidelines for Experimental Animal Welfare (MOST of People's Republic of China, 2006). The protocols of the animal experiments reported herein were approved by The Life Science Ethics Committee of Zhengzhou University. All efforts were made to minimize animal suffering during the course of these studies.

\section{Results}

\section{Examination of the larval surface protein stripping by} IFT

The IFT results were shown in Figure 1. The intense fluorescent staining at the cuticle surface of the normal

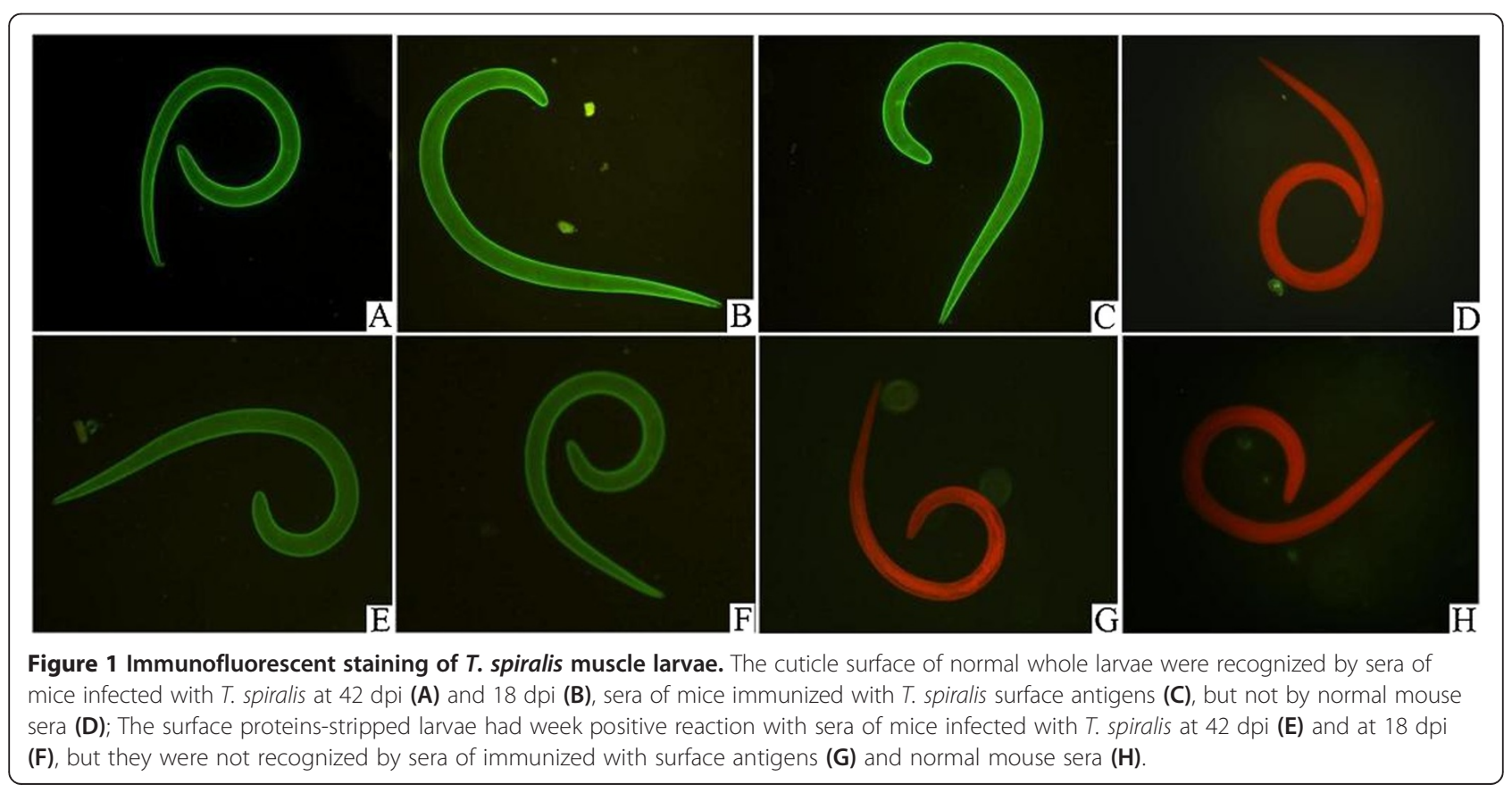


whole larvae was found when the sera of mice infected with $T$. spiralis at $42 \mathrm{dpi}$ as well as $18 \mathrm{dpi}$, and sera of mice immunized with surface antigens were used, but the larvae had negative reaction with sera of normal mice. The surface proteins-stripped larvae still had a weak positive reaction with sera of mice infected with T. spiralis at $42 \mathrm{dpi}$ and $18 \mathrm{dpi}$, but they had negative reaction with sera of immunized with surface antigens and normal mouse sera. The results of IFT indicated that surface proteins of muscle larvae were successfully stripped.

\section{Analysis of the surface proteins by SDS-PAGE and Western blotting}

The results of Coomassie blue stained SDS-PAGE gels of surface proteins from $T$. spiralis muscle larvae are shown in Figure 2A. The surface proteins had 12 protein bands with a molecular weight of $92,53,47,42,39,38,37$, $36,35,21,18$ and $16 \mathrm{kDa}$. We found that 7 protein bands $(42,39,36,35,21,18$ and $16 \mathrm{kDa})$ appeared in both surface and ES proteins, and 7 protein bands $(42,39,38,35$, 21,18 and $16 \mathrm{kDa}$ ) appeared in both surface and somatic proteins. The results of Western blotting of surface proteins are shown in Figure 2B. Seven protein bands (53, 47, $42,39,38,18$ and $16 \mathrm{kDa}$ ) of surface proteins were recognized by mouse infection sera at $18 \mathrm{dpi}$ and at $42 \mathrm{dpi}$. All 12 proteins of surface proteins were recognized by sera from mice immunized with surface proteins.

\section{2-DE analysis of surface proteins from $T$. spiralis muscle larvae}

The surface proteins of $T$. spiralis muscle larvae were separated on a 2-DE gel covering a pH 4-7 nonlinear, and the protein spots were visualized following Coomasie R-250 staining (Figure 3). A total of approximately 33 spots were detected on the Coomassie blue stained 2DE gels, with molecular weights (MW) varying from 10 to $66 \mathrm{kDa}$ and $\mathrm{pI}$ from 4 to 7 . Major protein spots were located in the acidic range ( $\mathrm{pH} 4-6)$ migrating at 30$60 \mathrm{kDa}$ and $10-20 \mathrm{kDa}$. The 2-DE was repeated three times, and the patterns were highly reproducible.

\section{Identification of proteins by MALDI-TOF/TOF-MS}

Twenty-seven of 33 protein spots were identified and characterized to correlate with 15 different proteins. Fourteen out of the 15 different proteins identified were T. spiralis proteins. The results of protein identification are shown in Table 1. Several different protein spots were identified as the same proteins by MALDI-TOF/ TOF-MS, such as spots 4, 6, 7, 9 and 15 were identified as deoxyribonuclease II family protein. Spots $17,19,20$, 23, 24 , and 25 were identified as the same conserved hypothetical protein.

\section{Functional categorization of surface proteins by gene ontology}

Gene Ontology (GO) signatures of 5 (partial P49 antigen, deoxyribonuclease II family protein, serine protease [gi|168805931], serine protease [gi|168805933], and serine proteinase) out of the 14 proteins identified were available. To further understand the functions of the proteins identified in this study, we queried against the InterPro databases and those resultant proteins were classified into molecular function and biological process according to GO hierarchy using WEGO (Figure 4).

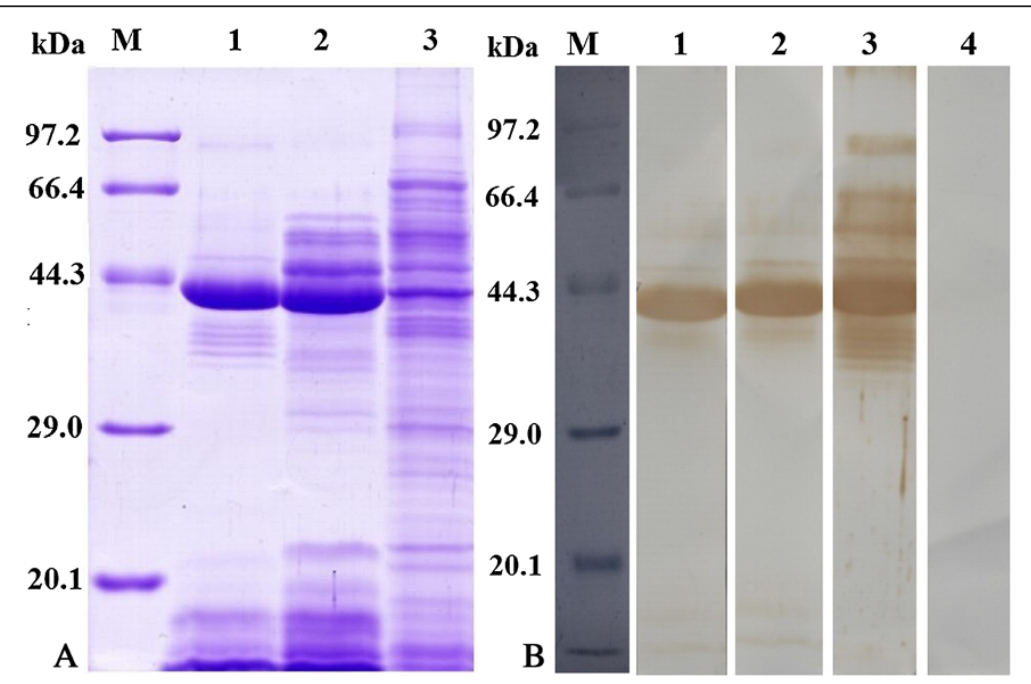

Figure 2 Analysis of surface proteins from $T$. spiralis muscle larvae. (A) SDS-PAGE analysis of surface proteins. Protein samples were separated in 12\% polyacrylamide gels under reducing conditions, and the gels were stained with Colloidal Coomassie blue G-250. M, low molecular weight protein marker; Lane 1, surface proteins; Lane 2, ES proteins; Lane 3, somatic proteins from whole larvae. (B) Western blotting of surface proteins. The surface proteins were recognize were recognized by sera from mice infected with T. spiralis at $18 \mathrm{dpi}$ (Lane 1) and at $42 \mathrm{dpi}$ (Lane 2) and sera from mice immunized with surface proteins (Lane 3), not by sera from normal mice (Lane 4). 


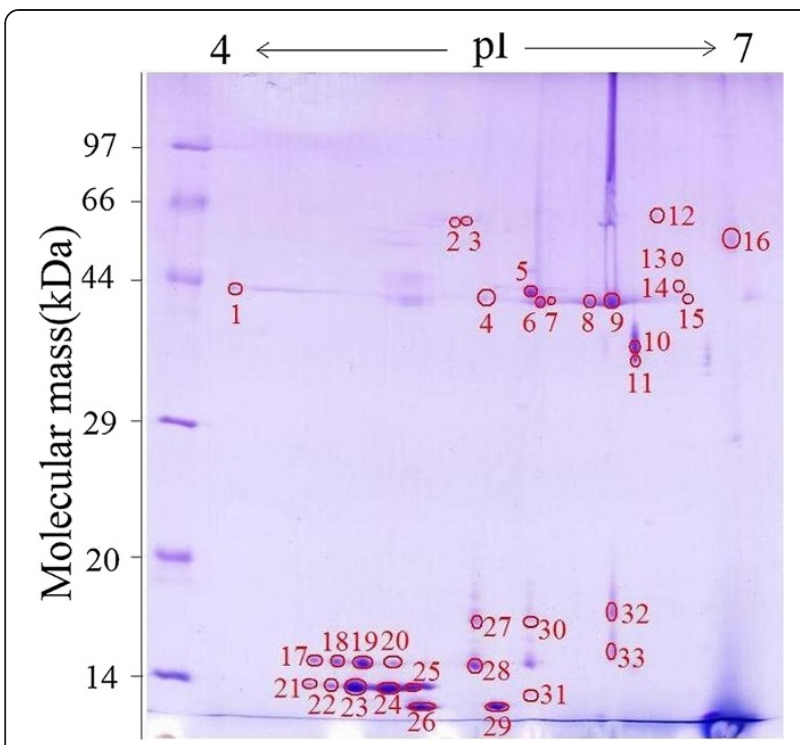

Figure 3 2-DE analysis of $T$. spiralis muscle larval surface proteins. 2-DE gel of surface proteins separated in the first dimension in the $\mathrm{pH}$ range $4-7$ and then in the second dimension on a $12 \%$ polyacrylamide gel. The gel was stained with Coomassie blue R-250, molecular weight standard is on the left, and pl values are indicated. Protein spots selected for further analysis are numbered.

For the molecular function ontology, the classification results showed that all the above- mentioned five Trichinella genes were annotated with catalytic activity (GO: 0003824). Catalytic activity specifically refers to hydrolase activity (GO: 0016787).

In the biological process category, five proteins of T. spiralis were related to metabolic process (GO: 0008152, 5 proteins, $100 \%$ of 5 annotated peptides) and cellular process (GO: 0009987, 2, 40\%). Most of the assigned metabolic process could be assigned to nitrogen compound metabolic process (GO: 0006807), catabolic process (GO: 0009056), macromolecule metabolic process (GO: 0043170), cellular metabolic process (GO: 0044237), primary metabolic process (GO: 0044238). The proteins in the cellular process group are related to cellular metabolic process (GO: 0044237). Most of the cellular and metabolic processes were related to synthesis and degradation of macromolecules, particularly carbohydrates, nucleotides and proteins, which might be associated with the invasion and development of $T$. spiralis infective larvae.

\section{Discussion}

The cuticle surface of $T$. spiralis muscle larvae is directly exposed to the host's immune system and present key target antigens that induce the host immune responses. As such, the surface antigens may play an important role in the invasion, immune evasion of the larvae and mutual adaptation between parasites and host immune response [29]. The surface proteins include a group of proteins that can signal various biological processes, including immune reactions, adhesion molecules, and enzymes. In this study, the IFT results showed that the surface proteins-stripped larvae were not recognized by sera of immunized mice with surface antigens, indicating that surface proteins of muscle larvae were successfully stripped and prepared. The results from SDS-PAGE showed that surface and ES proteins had the same 7 protein bands, and surface and somatic proteins also had the same 7 protein bands, suggesting that the partial surface proteins might derive from the ES proteins which were incorporated on the cuticle [7]. Western blotting analysis showed that seven protein bands of the surface proteins were recognized by mouse infection sera at $18 \mathrm{dpi}$, demonstrating the surface proteins might be used as early diagnostic antigens for trichinellosis.

T. spiralis infective larvae do not possess oral appendages or a spike [30], implying that the invasion of intestinal epithelial cells may not be simply a result of mechanical penetration but may be mediated by surface proteins and the oral secretions of the infective larvae [31]. The larval surface proteins may interact with intestinal epithelial cells and may play a key role during the larval invasion of intestinal epithelial cells. However, the specific protein molecules related with the larval invasion of enterocytes in $T$. spiralis surface proteins have not been identified [11].

In this study, our results demonstrated a protein profile of the $T$. spiralis surface proteins migrating as shown in Figure 3. A total of 33 protein spots were selected and identified by MALDI-TOF MS. Of these, 27 protein spots were identified, which represented 15 different proteins. Fourteen out of 15 different proteins were identified as T. spiralis proteins. Out of the 27 successfully identified protein spots, five spots $(4,6,7,9$ and 15) were identified as deoxyribonuclease II family protein, and they have the same MW and pI. Six spots (17, 19, 20, 23, 24, and 25) were identified as a conserved hypothetical protein, and they have the same pI but small differences in MW. Two spots (21 and 22) were identified as a conserved hypothetical protein, and they have the same MW and pI. Three spots $(27,28$, and 31) were identified as MBTsMLA019T7SEQ T. spiralis muscle stage larvae (BC) T. spiralis cDNA clone MBTsMLA019 5', mRNA sequence. In comparison, they have the same MW and pI. A previous study has also demonstrated that T. spiralis may express more than one isoforms of the protein and that a common precursor protein could undergo variable post-translational processing $[16,17,32]$. These modifications could be related to phosphorylation or acetylation of the proteins after translation, and they could be vital for the protein's biological functions, such as parasite survival, immune escape and immunopathogenesis. There is also a possibility that these 
Table 1 Identification of $T$. spiralis muscle larval surface protein by MALDI-TOF/TOF-MS

\begin{tabular}{|c|c|c|c|c|c|c|c|}
\hline Spot no. & Protein name & Accession no. & $\begin{array}{c}\text { Theoretical } \\
\mathrm{Mr} / \mathrm{pl}^{\mathrm{a}}\end{array}$ & $\begin{array}{l}\text { MOWSE } \\
\text { score }\end{array}$ & Coverage (\%) & $\begin{array}{l}\text { No. matched } \\
\text { peptides }\end{array}$ & $p$-value \\
\hline 1 & partial P49 antigen & gi|162542 & $34.5 / 5.23$ & 80 & 15 & 3 & 0.00032 \\
\hline 2 & Not identified & - & - & - & - & - & - \\
\hline 3 & hypothetical protein Tsp_08444 & gi|339247637 & 18.9/9.70 & 62 & 57 & 7 & 0.023 \\
\hline 4 & deoxyribonuclease II family protein & gi|339241449 & $38.1 / 5.95$ & 98 & 10 & 2 & $6.8 \mathrm{e}-006$ \\
\hline 5 & serine protease & gi|168805931 & $35.7 / 5.97$ & 245 & 18 & 4 & $1.1 \mathrm{e}-020$ \\
\hline 6 & deoxyribonuclease II family protein & gi|339241449 & $38.1 / 5.95$ & 382 & 22 & 6 & $2.1 \mathrm{e}-034$ \\
\hline 7 & deoxyribonuclease II family protein & gi|339241449 & $38.1 / 5.95$ & 315 & 22 & 6 & $1.1 \mathrm{e}-027$ \\
\hline 8 & Not identified & - & - & - & - & - & - \\
\hline 9 & deoxyribonuclease II family protein & gi|339241449 & $38.1 / 5.95$ & 447 & 28 & 7 & $6.6 \mathrm{e}-041$ \\
\hline 10 & $\begin{array}{l}\text { ps73f07.y1 T. spiralis adult pAMP1 v1 } \\
\text { T. spiralis cDNA 5', mRNA sequence }\end{array}$ & gi|21410467 & $22.3 / 4.83$ & 371 & 39 & 9 & $2 \mathrm{e}-032$ \\
\hline 11 & $\begin{array}{l}\text { ps97f02.y1 T. spiralis adult pAMP1 v1 } \\
\text { T. spiralis cDNA 5', mRNA sequence }\end{array}$ & gi|21414022 & $20.7 / 4.71$ & 369 & 38 & 9 & $3.2 \mathrm{e}-032$ \\
\hline 12 & $\begin{array}{l}\text { PREDICTED: keratin, type II cytoskeletal } 1 \\
\text { [Gorilla gorilla gorilla] }\end{array}$ & gi|160961491 & $66.0 / 8.15$ & 232 & 36 & 12 & $1.4 \mathrm{e}-016$ \\
\hline 13 & serine protease & gi|168805933 & $48.7 / 6.33$ & 145 & 9 & 2 & $1.1 \mathrm{e}-010$ \\
\hline 14 & serine proteinase & gi|13641204 & $48.7 / 6.33$ & 116 & 12 & 5 & $8.4 \mathrm{e}-008$ \\
\hline 15 & deoxyribonuclease II family protein & gi|339241449 & $38.1 / 5.95$ & 312 & 30 & 9 & $2.1 \mathrm{e}-027$ \\
\hline 16 & $53 \mathrm{kDa}$ excretory/secretory antigen & gi|805126 & $4.71 / 8.42$ & 280 & 21 & 8 & $3.3 e-024$ \\
\hline 17 & conserved hypothetical protein & gi|339258426 & $13.5 / 4.54$ & 121 & 19 & 2 & $2.6 \mathrm{e}-008$ \\
\hline 18 & Not identified & - & - & - & - & - & - \\
\hline 19 & conserved hypothetical protein & gi|339258426 & $13.7 / 4.54$ & 209 & 29 & 3 & $4.2 \mathrm{e}-017$ \\
\hline 20 & conserved hypothetical protein & gi|339258426 & 13.5/4.54/ & 205 & 42 & 4 & $1.1 \mathrm{e}-016$ \\
\hline 21 & conserved hypothetical protein & gi|316966355 & $13.5 / 4.54$ & 92 & 30 & 2 & $2.2 e-005$ \\
\hline 22 & conserved hypothetical protein & gi|316966355 & $13.5 / 4.54$ & 70 & 19 & 2 & 0.0035 \\
\hline 23 & conserved hypothetical protein & gi|339258426 & $13.5 / 4.54$ & 231 & 29 & 3 & 2.6e-019 \\
\hline 24 & conserved hypothetical protein & gi|339258426 & $13.5 / 4.54$ & 254 & 59 & 5 & $1.3 e-021$ \\
\hline 25 & conserved hypothetical protein & gi|339258426 & 13.54 .54 & 248 & 59 & 5 & $5.3 e-021$ \\
\hline 26 & Not identified & - & - & - & - & - & - \\
\hline 27 & $\begin{array}{c}\text { MBTsMLA019T7SEQ T. spiralis muscle stage larvae (BC) } \\
\text { T. spiralis CDNA clone MBTsMLA019 5', mRNA } \\
\text { sequence }\end{array}$ & gi|13198997 & 19.9/4.76 & 345 & 38 & 6 & $8.1 \mathrm{e}-030$ \\
\hline 28 & $\begin{array}{c}\text { MBTsMLA019T7SEQ T. spiralis muscle stage larvae (BC) } \\
\text { T. spiralis CDNA clone MBTsMLA019 5', mRNA } \\
\text { sequence }\end{array}$ & gi|13198997 & $19.9 / 4.76$ & 359 & 38 & 6 & $3.2 \mathrm{e}-031$ \\
\hline 29 & Not identified & - & - & - & - & - & - \\
\hline 30 & Not identified & - & - & - & - & - & - \\
\hline 31 & $\begin{array}{c}\text { MBTsMLA019T7SEQ T. spiralis muscle stage larvae (BC) } \\
\text { T. spiralis CDNA clone MBTsMLA019 5', mRNA } \\
\text { sequence }\end{array}$ & gi|13198997 & 19.9/4.76 & 423 & 55 & 6 & $1.3 e-037$ \\
\hline 32 & $\begin{array}{c}\text { TPAF-aac52c09.g1 T. spiralis_EST T. spiralis CDNA 5', } \\
\text { mRNA sequence }\end{array}$ & gi|157957485 & $21.6 / 9.48$ & 382 & 57 & 7 & $1.6 \mathrm{e}-033$ \\
\hline 33 & $\begin{array}{l}\text { ps19d01.y1 T. spiralis ML CMVsport jasmer } \\
\text { T. spiralis cDNA 5', mRNA sequence }\end{array}$ & gi|148310851 & $17.7 / 10.32$ & 223 & 53 & 6 & $1.3 e-017$ \\
\hline
\end{tabular}

${ }^{\mathrm{a}}$ Theoretical molecular mass $(\mathrm{kDa})$ and isoelectric point $(\mathrm{pl})$. 


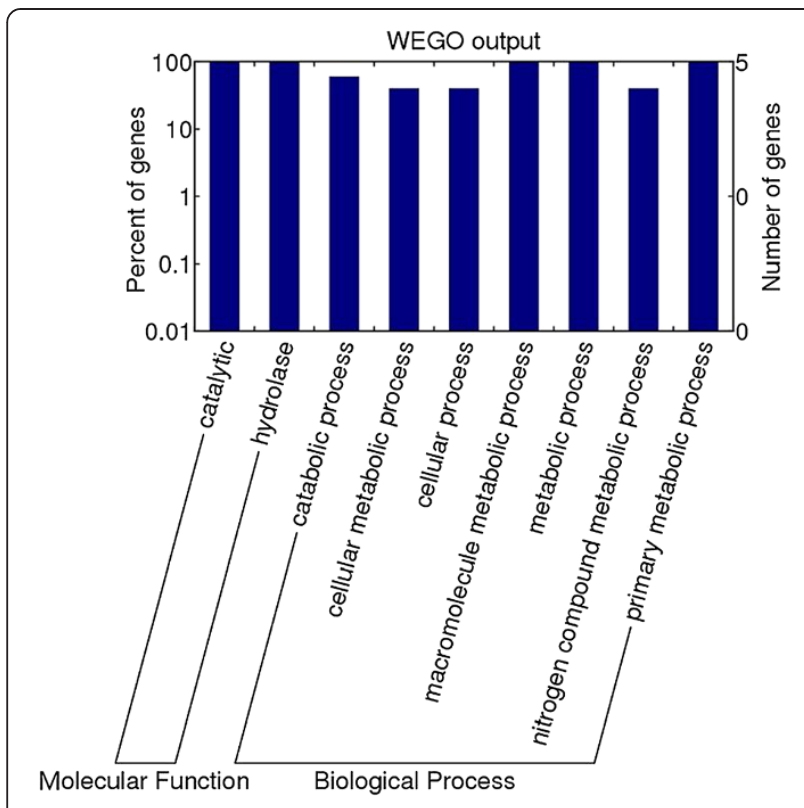

Figure $4 \mathrm{GO}$ categories of $T$. spiralis muscle larval surface proteins. The proteins were classified into molecular function and biological process by WEGO according to their GO signatures. The number of genes denotes that of proteins with $\mathrm{GO}$ annotations.

proteins are members of the same protein family which share functional domains. Six protein spots $(2,8,18,26$, 29 and 30) failed to match the proteins to T. spiralis ESTs or any sequence of other species of the genus Trichinella, which may be due to the low concentrations of the proteins, which therefore failed to produce high quality mass spectrometric data. It is also possibly because the proteins of the six spots were not included in the databases and these proteins have not yet been described.

In order to provide a comprehensive understanding of the roles of $T$. spiralis surface proteins, the proteins identified were functionally categorized based on the GO annotation of biological process and molecular functions. Accordingly, the proteins identified by MALDI-TOF MS might demonstrate their importance and contribution in the process of larval invasion and immune evasion. The classification results of the 14 Trichinella genes showed that five genes were annotated with putative molecular functions. All the five T. spiralis proteins (partial P49 antigen, deoxyribonuclease II family protein, two serine proteases, and serine proteinase) encoded by these genes have hydrolase activity. The results suggested that the larval invasion of intestinal epithelial cells was possibly mediated by these hydrolase in the larval surface proteins [31,33]. Out of the 14 different $T$. spiralis proteins identified in this study, 9 proteins had no assigned $\mathrm{GO}$ terms in the GO database. This is partially due to the limitation of the coverage of the current GO annotation system, and also due to some novel proteins previously described only as putative open reading frames (ORFs).
The partial P49 antigen of $T$. spiralis has been cloned, characterized, and expressed in Escherichia coli by recombinant DNA methods [34]. The recombinant P49 is a potentially valuable antigen both for vaccine development and immunodiagnosis. The deoxyribonuclease II family protein is known to be a lysosomal enzyme, introduce single and double-stranded breaks into supercoiled plasmids in the presence of EDTA, and mediate internucleosomal DNA digestion characteristic of apoptosis following intracellular acidification [35,36]. Serine proteases are important in a wide variety of biological processes, including digestion, blood coagulation and fibrinolysis. They are enzymes that cleave peptide bonds in proteins, in which serine serves as the nucleophilic amino acid at the enzyme's active site [37]. In parasites, serine proteases are known to be involved in the invasion of host tissues and cells [38], and in nematodes are likely to be important in molting. Several secreted serine proteases have been identified in T. spiralis ES proteins, including the trypsin-like $45 \mathrm{kDa}$ antigen and the serine protease TspSP-1 [39,40]. Our previous studies showed that when $T$. spiralis muscle larvae were activated by bile and co-cultured with intestinal epithelial cells, the transcription and expression level of a serine protease gene was obviously up-regulated, compared with the untreated normal muscle larvae [41-43]. The results of the present study further suggested that the serine proteases might be related with the larval invasion of intestinal epithelial cells, which is needed to be confirmed in further experiments.

\section{Conclusions}

This study showed that $T$. spiralis muscle larval surface proteins had a total of approximately 33 proteins spots with pI 4-7 and MW $10-66 \mathrm{kDa}$. Out of the 14 proteins identified as T. spiralis proteins, 5 proteins (partial P49 antigen, deoxyribonuclease II family protein, two serine proteases, and serine proteinase) had catalytic and hydrolase activity. These $T$. spiralis surface proteins identified might be invasion-related proteins, early diagnostic antigens for trichinellosis and targets for a vaccine.

\section{Competing interests}

The authors declare that they have no competing interests.

\section{Authors' contributions}

JC, ZQW and MYL conceived and designed the experiments. JC, RDL, LW, XZ, and PJ performed the experiments. JC RDL, MYL, and ZQW analyzed the data and wrote the manuscript. All authors read and approved the final version of the manuscript.

\section{Acknowledgements}

This work was supported by the National Natural Science Foundation of China (No. 81271860 and 81371843 ).

\section{Author details}

'Department of Parasitology, Medical College, Zhengzhou University, 40 Daxue Road, Zhengzhou 450052, P. R. China. ${ }^{2}$ Key Lab of Zoonosis Research, 
Ministry of Education, Institute of Zoonosis, Jilin University, Changchun 130062, P. R. China.

Received: 28 October 2013 Accepted: 4 December 2013 Published: 16 December 2013

\section{References}

1. Murrell KD, Pozio E: Worldwide occurrence and impact of human trichinellosis, 1986-2009. Emerg Infect Dis 2011, 17(12):2194-2202.

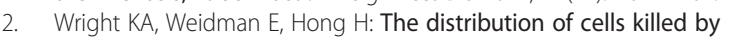
Trichinella spiralis in the mucosal epithelium of two strains of mice. J Parasitol 1987, 73(5):935-939.

3. Wang B, Wang ZQ, Jin J, Ren HJ, Liu LN, Cui J: Cloning, expression and characterization of a Trichinella spiralis serine protease gene encoding a 35.5 kDa protein. Exp Parasitol 2013, 134(2):148-154.

4. Zhang YL, Wang ZQ, Li LG, Cui J: Molecular characterization of Trichinella spiralis aminopeptidase and its potential as a novel vaccine candidate antigen against trichinellosis in BALB/c mice. Parasit Vectors 2013, 6(1):246.

5. Gagliardo LF, McVay CS, Appleton JA: Molting, ecdysis, and reproduction of Trichinella spiralis are supported in vitro by intestinal epithelial cells. Infect Immun 2002, 70(4):1853-1859.

6. Ren HJ, Cui J, Wang ZQ, Liu RD: Normal mouse intestinal epithelial cells as a model for the in vitro invasion of Trichinella spiralis infective larvae. PLoS One 2011, 6(10):e27010.

7. Ortega-Pierres G, Chayen A, Clark NW, Parkhouse RM: The occurrence of antibodies to hidden and exposed determinants of surface antigens of Trichinella spiralis. Parasitology 1984, 88(2):359-369.

8. Grencis RK, Crawford C, Pritchard DI, Behnke JM, Wakelin D: Immunization of mice with surface antigens from the muscle larvae of Trichinella spiralis. Parasite Immunol 1986, 8(6):587-596.

9. Butterworth AE: Cell-mediated damage to helminths. Adv Parasitol 1984, 23:143-235.

10. Bolas-Fernandez F, Corral Bezara LD: TSL-1 antigens of Trichinella: an overview of their potential role in parasite invasion, survival and serodiagnosis of trichinellosis. Res Vet Sci 2006, 81(3):297-303.

11. Nagano I, Wu Z, Takahashi Y: Functional genes and proteins of Trichinella spp. Parasitol Res 2009, 104(2):197-207.

12. Mitreva M, Jasmer DP, Zarlenga DS, Wang Z, Abubucker S, Martin J, Taylor $C M$, Yin $Y$, Fulton $L$, Minx $P$, et al: The draft genome of the parasitic nematode Trichinella spiralis. Nat Genet 2011, 43(3):228-235.

13. Wu Z, Nagano I, Takahashi Y: A panel of antigens of muscle larvae of Trichinella spiralis and T. pseudospiralis as revealed by two-dimensional western blot and immunoelectron microscopy. Parasitology 1999, 118(6):615-622.

14. Dea-Ayuela MA, Ubeira FM, Pitarch A, Gil C, Martinez-Fernandez AR, Bolas F: A comparison of antigenic peptides in muscle larvae of several Trichinella species by two-dimensional western-blot analysis with monoclonal antibodies. Parasite 2001, 8(2 Suppl):S117-S119.

15. Nareaho A, Ravanko K, Holtta E, Sukura A: Comparative analysis of Trichinella spiralis and Trichinella nativa proteins by two-dimensional gel electrophoresis. Parasitol Res 2006, 98(4):349-354.

16. Robinson MW, Greig R, Beattie KA, Lamont DJ, Connolly B: Comparative analysis of the excretory-secretory proteome of the muscle larva of Trichinella pseudospiralis and Trichinella spiralis. Int J Parasitol 2007, 37(2):139-148

17. Bien J, Nareaho A, Varmanen P, Gozdzik K, Moskwa B, Cabaj W, Nyman TA, Savijoki K: Comparative analysis of excretory-secretory antigens of Trichinella spiralis and Trichinella britovi muscle larvae by two-dimensional difference gel electrophoresis and immunoblotting. Proteome Sci 2012, 10(1):10.

18. Robinson MW, Gare DC, Connolly B: Profiling excretory/secretory proteins of Trichinella spiralis muscle larvae by two-dimensional gel electrophoresis and mass spectrometry. Vet Parasitol 2005, 132(1-2):37-41.

19. Wang L, Wang ZQ, Hu DD, Cui J: Proteomic analysis of Trichinella spiralis muscle larval excretory-secretory proteins recognized by early infection sera. Biomed Res Int 2013, 2013:139745.

20. Li F, Cui J, Wang ZQ, Jiang P: Sensitivity and optimization of artificial digestion in the inspection of meat for Trichinella spiralis. Foodborne Pathog Dis 2010, 7(8):879-885.

21. Gamble HR, Bessonov AS, Cuperlovic K, Gajadhar AA, van Knapen F, Noeckler K, Schenone H, Zhu X: International Commission on
Trichinellosis: recommendations on methods for the control of Trichinella in domestic and wild animals intended for human consumption. Vet Parasitol 2000, 93(3-4):393-408.

22. Pritchard DI, Crawford CR, Duce IR, Behnke JM: Antigen stripping from the nematode epicuticle using the cationic detergent cetyltrimethylammonium bromide (CTAB). Parasite Immunol 1985, 7(6):575-585.

23. Wang L, Wang ZQ, Cui J: Protein changes in Trichinella spiralis muscle larvae in vitro induced by bovine bile. Vet Parasitol 2013, 194(2-4):164-167.

24. Bradford MM: A rapid and sensitive method for the quantitation of microgram quantities of protein utilizing the principle of protein-dye binding. Anal Biochem 1976, 72:248-254.

25. Cui J, Ren HJ, Liu RD, Wang L, Zhang ZF, Wang ZQ: Phage-displayed specific polypeptide antigens induce significant protective immunity against Trichinella spiralis infection in BALB/c mice. Vaccine 2013, 31(8):1171-1177.

26. Wang SW, Wang ZQ, Cui J: Protein change of intestinal epithelial cells induced in vitro by Trichinella spiralis infective larvae. Parasitol Res 2011, 108(3):593-599.

27. Ni XD, Wang N, Liu YJ, Lu CP: Immunoproteomics of extracellular proteins of the Aeromonas hydrophila China vaccine strain J-1 reveal a highly immunoreactive outer membrane protein. FEMS Immunol Med Microbiol 2010, 58(3):363-373.

28. Li G, Waltham M, Anderson NL, Unsworth E, Treston A, Weinstein JN: Rapid mass spectrometric identification of proteins from two-dimensional polyacrylamide gels after in gel proteolytic digestion. Electrophoresis 1997, 18(3-4):391-402.

29. Bruschi F, Chiumiento L: Trichinella inflammatory myopathy: host or parasite strategy? Parasit Vectors 2011, 4:42.

30. Bruce RG: Structure of the esophagus of the infective juvenile and adult Trichinella spiralis. J Parasitol 1970, 56(3):540-549.

31. ManWarren T, Gagliardo L, Geyer J, McVay C, Pearce-Kelling S, Appleton J: Invasion of intestinal epithelia in vitro by the parasitic nematode Trichinella spiralis. Infect Immun 1997, 65(11):4806-4812.

32. Todorova VK: Proteolytic enzymes secreted by larval stage of the parasitic nematode Trichinella spiralis. Folia Parasitol (Praha) 2000, 47(2):141-145.

33. Ren HJ, Liu RD, Wang ZQ, Cui J: Construction and use of a Trichinella spiralis phage display library to identify the interactions between parasite and host enterocytes. Parasitol Res 2013, 112(5):1857-1863.

34. Su XZ, Prestwood AK, McGraw RA: Cloning and expression of complementary DNA encoding an antigen of Trichinella spiralis. Mol Biochem Parasitol 1991, 45(2):331-336.

35. Shiokawa D, Ohyama H, Yamada T, Takahashi K, Tanuma S: Identification of an endonuclease responsible for apoptosis in rat thymocytes. Eur J Biochem 1994, 226(1):23-30.

36. Barry MA, Eastman A: Identification of deoxyribonuclease II as an endonuclease involved in apoptosis. Arch Biochem Biophys 1993, 300(1):440-450.

37. Hedstrom L: Serine protease mechanism and specificity. Chem Rev 2002, 102(12):4501-4524

38. Dzik JM: Molecules released by helminth parasites involved in host colonization. Acta Biochim Pol 2006, 53(1):33-64.

39. Romaris F, North SJ, Gagliardo LF, Butcher BA, Ghosh K, Beiting DP, Panico M, Arasu P, Dell A, Morris HR, et al: A putative serine protease among the excretory-secretory glycoproteins of L1 Trichinella spiralis. Mol Biochem Parasito/ 2002, 122(2):149-160.

40. Robinson MW, Connolly B: Proteomic analysis of the excretory-secretory proteins of the Trichinella spiralis L1 larva, a nematode parasite of skeletal muscle. Proteomics 2005, 5(17):4525-4532.

41. Liu RD, Wang ZQ, Wang L, Long SR, Ren HJ, Cui J: Analysis of differentially expressed genes of Trichinella spiralis larvae activated by bile and cultured with intestinal epithelial cells using real-time PCR. Parasitol Res 2013, 112(12):4113-4120.

42. Ren HJ, Cui J, Yang W, Liu RD, Wang ZQ: Identification of differentially expressed genes of Trichinella spiralis larvae after exposure to host intestine milieu. PLoS One 2013, 8(6):e67570.

43. Wang L, Wang ZQ, Cui J: Proteomic analysis of the changed proteins of Trichinella spiralis infective larvae after co-culture in vitro with intestinal epithelial cells. Vet Parasitol 2013, 194(2-4):160-163.

doi:10.1186/1756-3305-6-355

Cite this article as: Cui et al.: Proteomic analysis of surface proteins of Trichinella spiralis muscle larvae by two-dimensional gel electrophoresis and mass spectrometry. Parasites \& Vectors 2013 6:355. 